Int. J. Dev. Biol. 49: 43-47 (2005)

doi: $10.1387 / \mathrm{ijdb} .041920 \mathrm{zz}$

Short Communication

\title{
A generalized caspase inhibitor disrupts early mammalian development
}

\author{
ZAHRA ZAKERI*,1 RICHARD A. LOCKSHIN², LUIS-MIGUEL CRIADO-RODRÍGUEZ ${ }^{3}$ and CARLOS MARTÍNEZ-A ${ }^{3}$ \\ ${ }^{1}$ Department of Biology, Queens College and Graduate Center of the City University of New York, New York, USA, \\ ${ }^{2}$ Department of Biological Sciences, St. John's University, New York, USA and ${ }^{3}$ Departamento de Inmunología y Oncología, Centro \\ Nacional de Biotecnologia, Campus de la Universidad Autónoma de Madrid, Madrid, Spain
}

\begin{abstract}
The role and mechanism of cell death in early mammalian embryos is not well understood. In mouse embryos collected after fertilization and maintained in vitro until blastula formation, two instances of cell death are observed: the polar bodies and one or two cells near the equator, at the junction of the inner cell mass to the prototrophoblast. Inhibitors of caspases do not block the death of the polar bodies. Inhibitors of caspases 3, 7 and 8 do not affect post-cavitation death, but the pan-caspase inhibitor zVAD-FMK, when applied at the 1-2 cell stage, causes an expansion of post-cavitation death and ultimately malformation or death of the embryo. Our results indicate that the early deaths are not caspase-dependent and that there is a role for caspase activity in early embryos, which is not related to cell death.
\end{abstract}

KEY WORDS: mammalian embryo, pre-implantation, apoptosis, caspase, inhibitor

The caspase cascade is a major component of apoptosis in development and in many other situations. Presently most researchers assume that caspases function only in cell death, even though related family members serve, for instance, in the activation pathway for immunologically competent cells. If caspases have other roles in cell function, it is appropriate to ask what roles they play in early development. There have been a number of reports on cell death in pre-implantation embryos. The polar bodies begin to die during earliest cleavage, but cell death in the pre-implantation embryo itself begins at about the 8-cell stage. The cell death in the embryo is apoptotic by the criterion of TUNEL positivity (Matwee, Betts and King, 2000). The expression of caspases 2 and 3 (but not caspase 1) has been shown for blastocysts (Weil, Jacobson, Coles, Davies, Gardner, Raff and Raff, 1996). A few cells routinely die in the blastocyst (Handyside and Hunter, 1986) and this number is increased in suboptimal conditions such as maternal hyperglycemia (Pampfer, Vanderheyden, McCracken, Vesela and De Hertogh, 1997; Moley, Chi, Knudson, Korsmeyer and Mueckler, 1998) or in vitro fertilization (Jurisicova, Rogers, Fasciani, Casper and Varmuza, 1998) as well as when toxins such as staurosporine and cycloheximide are administered (Weil, Jacobson, Coles, Davies, Gardner, Raff and Raff, 1996). However, pre-implantation development is not disrupted by individually knocking out Bcl-2, Bax, Bcl-X, Bcl-W, or caspases 1,2,3,8,9, or 11 (Pampfer and Donnay, 1999).

During embryonic development of mammals, zygotic genes are translated as early as the 2 -cell stage. The first sign of cell death is seen at the $6-8$ cell stage, followed by further deaths at the blastula stage. It is believed that cell death in these stages relates to cavitation and blastocyst formation and the elimination of potential trophectoderm cells from the inner cell mass (Pierce, Lewellyn and Parchment, 1989). Although cavitation occurs synchronously with cell death, at least in embryoid bodies, this death requires apoptosis-inducing factor but is independent of caspase expression and does not manifest all the characteristics of apoptosis (Joza, Susin, Daugas, Stanford, Cho, Li, Sasaki, Elia, Cheng, Ravagnan, Ferri, Zamzami, Wakeham, Hakem, Yoshida, Kong, Mak, Zuniga-Pflucker, Kroemer and Penninger, 2001).

To determine if specific caspases have different roles in the different stages of preimplantation mouse embryos, we exposed the developing embryos to known caspase inhibitors, the fluoromethylketone (FMK) derivatives of tetrapeptide substrates. We find that the inhibitor zVAD-FMK has major effects on mammalian pre-implantation development, at a time when cell death is not a factor and that at least some apoptotic cell deaths are not preventable by caspase inhibitors (in fact caspase inhibition seems to increase cell death). These effects suggest that either the inhibitors disrupt enzymes other than caspases or that caspase activity is important in situations other than apoptosis. Since zVAD

Abbreviations used in this paper: FMK, fluoromethylketone; zVAD, Nbenzyloxycarbonyl-Val-Ala-Asp-fluoromethylketone.

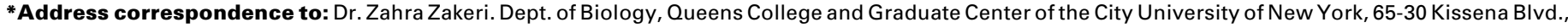
Flushing, NY 11367, USA. Fax: +1-718-990-5958. e-mail: zahra_zakeri@qc.edu
} 


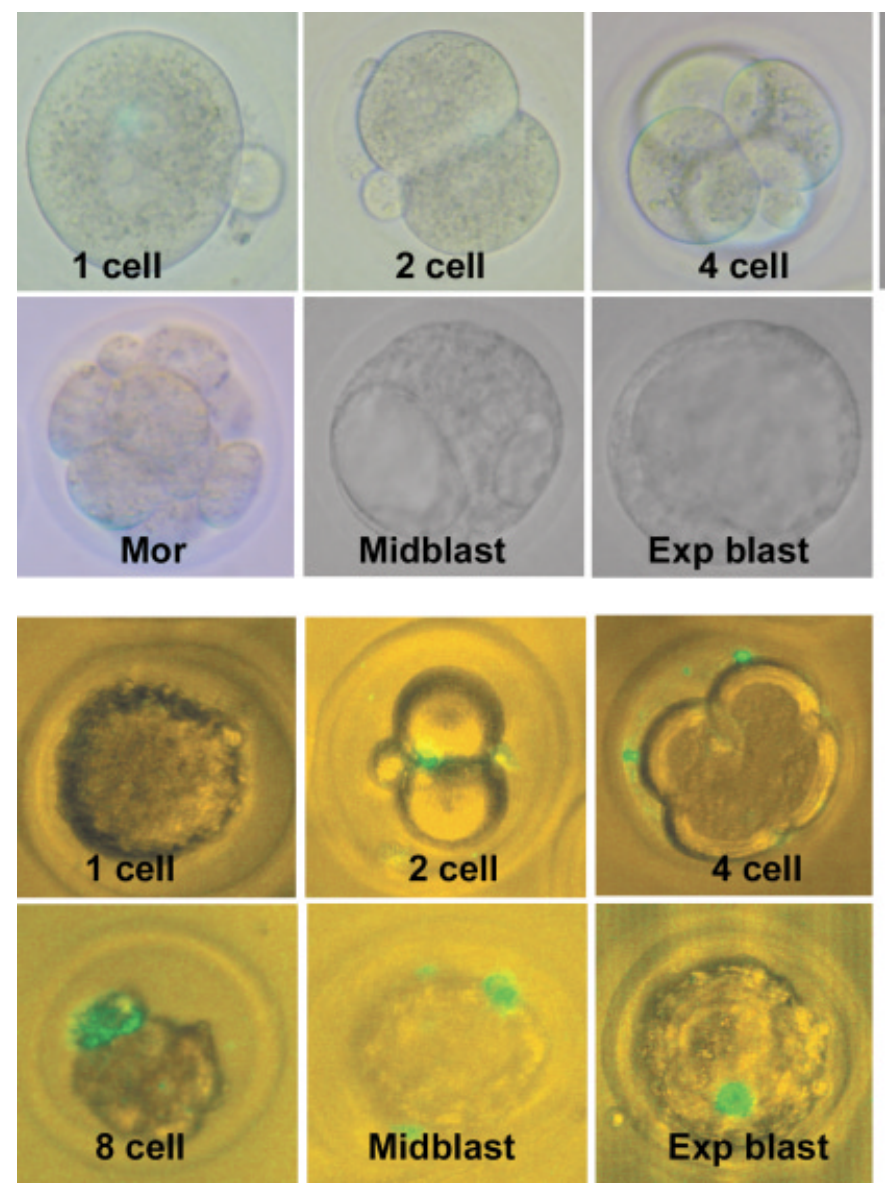

is most toxic when applied at the 1-2 cell stage but the effect is not manifest until cavitation, it appears either that an early perhaps proteolytic change prepares the embryo for eventual cavitation, or that the alteration of the cell death pattern that is established at cavitation proves to be lethal. In either event, some caution concerning the assumption of absolute correspondence between caspases and cell death is warranted.

\section{ZVAD-FMK prevents the progression of the 8-cell em- bryo into blastula stage}

We investigated the role of caspase-like enzymes in the developing embryo by using the fluormethylketone versions of the different inhibitors, DEVD, YVAD and zVAD. DEVD inhibits caspase 3, which recognizes the site DEVD-G; caspase 10 and to a lesser extent other caspases (Cryns, V. L. and Yuan, J. Y., 1998; Harvey and Kumar, 1998; Thornberry, N. A., 1999; Vaux, 1999, 2004). YVAD inhibits predominantly caspase 1, which recognizes YVAD-G and YVPD-S. zVAD more generically inhibits a broad range of caspases, but especially caspase 8 . Embryos at the 8-cell stage were retrieved from the mother and placed in media containing M2 alone, or M2 supplemented with $100 \mu \mathrm{M}$ DEVD, YVAD, or zVAD respectively. After $24 \mathrm{hr}$ incubation the developmental progression was examined by microscopy. Almost $100 \%$ of the control embryos reached late to expanded

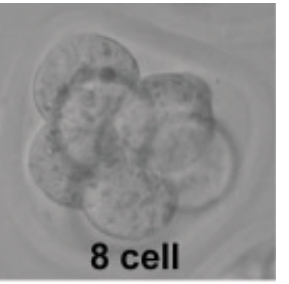

Fig. 1. Normal development of mouse embryos. Top panel, left to right: cultured mouse embryos at the following stages: 1-cell, 2-cell, 4-cell, 8-cell, morula, midblastula, expanded blastula. Polarbodies are readily visible at 1-cell and 2-cell stages. Lower panel: similar series of embryos exposed to annexin $V$ as described in Experimental Procedures. The panels represent, sequentially, 1-cell, 2-cell, 4-cell, 8-cell, midblastula and expanded blastula. The polar bodies exteriorize phosphatidylserine by the 2-cell stage. At compaction and in early blastula, dead cells are present and at expanded blastula, cell death is seen where the inner cell mass meets the trophectoderm. Either one or two dead cells are seen at this time. When there are two dead cells, they are at opposite poles at the same latitude.

blastula stage ( $88 \%$ of all embryos, $100 \%$ of those reaching 2-cell stage-Tables 1,2). DEVD- and YVAD-treated embryos were comparable to the control, but the embryos treated with zVAD during their first cleavage divisions reached only the early to mid morula stage (Tables 1,2). This result suggests that a progression of development of the embryo from the 8 cell stage to the blastula and more specifically from morula stage to blastula and that this specific caspase is not inhibited by YVAD or DEVD. Alternatively, zVAD may have heretofore unsuspected effects beyond the inhibition of caspases. Much occurs during the formation of blastula from a morula, such as movement of the cells and formation of the fluid filled blastocoele. It is believed that in addition to cell movement, cell death also contributes to the formation of the blastocoele (Pierce, Lewellyn and Parchment, 1989). It is possible that factors inhibited by the inhibition of caspases by zVAD contribute to the formation of the cavity by affecting either cell movement or cell death.

\section{Cell death in the developing pre-implantation embryo is not caspase-dependent}

Cell death is reported to occur naturally beginning at the 8-cell stage (Handyside and Hunter, 1986; Hardy, Handyside and Winston, 1989; Hardy, 1997). We therefore asked if the inhibitors affect these deaths. In our hand the complete timing of blastula development from a fertilized egg took 4 days (Fig. 1, top panel). We examined the normal pattern of cell death in pre-implantation embryos by using annexin $\mathrm{V}$ as a marker of apoptosis. As early as the two-cell stage, at least one polar body is annexin positive (Fig. 1 bottom panel, 2 cells). Martinez et al. (Martinez, Rienzi, lacobelli, Ubaldi, Mendoza, Greco and Tesarik, 2002) observed caspase activity in the second polar body of healthy human embryos, but otherwise they saw caspase activity only in apparent apoptotic fragments seen in unhealthy embryos. Within the embryo, the first
TABLE 1

NUMBER OF EMBRYOS REACHING BLAS TOCYST WHEN EXPOSED AT DIFFERENT STAGES

\begin{tabular}{lcc} 
Treatment & \multicolumn{2}{c}{ Blastocysts/embryos } \\
\hline Stage at first exposure & 8 cell & $1-2$ cell \\
Control & $18 / 18$ & $11 / 11$ \\
DEVD & $19 / 19$ & $11 / 11$ \\
YVAD & $19 / 19$ & $11 / 11$ \\
ZVAD & $3 / 19$ & $0 / 11$ \\
\hline
\end{tabular}

TABLE 2

NUMBER OF EMBRYOS PASSING LANDMARK AT APPROPRIATE TIME WHEN EXPOSED AT 1-2 CELL STAGE

\begin{tabular}{lllll} 
Treatment 2-cell 4-cell 8-cell Blastocysts/embryos \\
\hline
\end{tabular} \begin{tabular}{lllll}
\hline Control, 1 cell & $44 / 50$ & $44 / 50$ & $44 / 50$ & $44 / 50$
\end{tabular} Control $\quad 11 / 11 \quad 11 / 11 \quad 11 / 11 \quad 11 / 11$ DEVD $\quad 11 / 11 \quad 11 / 11 \quad 11 / 11 \quad 11 / 11$ $\begin{array}{lllll}\text { YVAD } & 11 / 11 & 11 / 11 & 11 / 11 & 11 / 11\end{array}$

$\begin{array}{lllll}\text { zVAD } & 11 / 11 & 2 / 11 & 0 / 11 & 0 / 11\end{array}$


detectable dead cell is found at the 8 cell stage (Fig. 1 bottom panel, 8 cells). The pattern of cell death seen in the 8 cell embryos does not change with short term (3-6 hours) incubation with different caspase inhibitors (data not shown) either in the polar body or the embryo. This suggests that the type of cell death in these stages is independent of caspases that are inhibited by these inhibitors. It is of course possible that the zVAD-FMK failed to inhibit the caspases, but since it produced a biological effect that was seen, though at lower frequency, at half the concentration (data not shown) and the $100 \mu \mathrm{M}$ concentration is that commonly used for maximum inhibition. Joza et al. (Joza, Susin, Daugas, Stanford, Cho, Li, Sasaki, Elia, Cheng, Ravagnan, Ferri, Zamzami, Wakeham, Hakem, Yoshida, Kong, Mak, Zuniga-Pflucker, Kroemer and Penninger, 2001) came to a similar conclusion, demonstrating that cell death during cavitation of embryoid bodies was independent of caspase activity and Martinez et al., (Martinez, Rienzi, lacobelli, Ubaldi, Mendoza, Greco and Tesarik, 2002) saw no caspase activity in healthy early human embryos.

\section{The action of zVAD involves the determination of em- bryonic fate at an early stage}

Since inhibition of caspases affected the progression of embryonic development from 8 cell stage to blastula, we attempted to determine the stage at which the inhibitors acted. For this determination we exposed the embryo to different caspase inhibitors over a timed series. One-cell zygotes were retrieved from the mothers and allowed to develop in vitro. The developing embryos were exposed transiently (through one cell division) to inhibitors beginning at one cell, stage and examined four days later, at which time 98-100\% of embryos in the control have reached the blastulae stage. The experimental embryos were subjected to the caspase inhibitors at one cell to two-cell stage (E1-E2); two cell to four cell stage (E2-E4); Four cell to eight cell stage (E4-E8); and 8 cell (E8) to blastula stage. After exposure at each interval, the embryos were removed, washed and transferred to media devoid of inhibitor and allowed to continue their development. Virtually $100 \%$ of the embryos exposed to DEVD or YVAD reached mid to late blastula, similar to the controls regardless of the period of exposure. Two (22\%) of embryos treated with YVAD at the first cleavage were lost, but 132 embryos exposed to YVAD, DEVD, or nothing (control media alone) reached blastula stage (Table 3 ). However this was not the case when zVAD was used as an inhibitor. Exposure to zVAD prior to the 8-cell stage invariably blocked progression to blastocyst (Table 3). Fifty-five percent of 8-cell embryos exposed to zVAD reached an early, if somewhat abnormal, blastocyst stage. We did not attempt to follow them further. We repeated the experiment three times with consistent results as represented in Figure 2.

\section{TABLE 3}

\begin{tabular}{lcccc}
$\begin{array}{l}\text { NUMBER OF EMBRYOS REACHING BLASTOCYST WHEN } \\
\text { EXPOSED AT VARIOUS AGES }\end{array}$ \\
$\begin{array}{l}\text { Treatment } \\
\text { Exp. at 1-cell }\end{array}$ & Exp. at 2-cell & Exp. at 4 cell Exp. at 8-cell \\
\hline Control & $11 / 11$ & $11 / 11$ & $11 / 11$ & $11 / 11$ \\
DEVD & $11 / 11$ & $11 / 11$ & $11 / 11$ & $11 / 11$ \\
YVAD & $9 / 11$ & $11 / 11$ & $11 / 11$ & $11 / 11$ \\
zVAD & $0 / 11$ & $0 / 11$ & $0 / 11$ & $5 / 11^{*}$ \\
\hline
\end{tabular}

*6/11 morula; $5 / 11$ early blastula

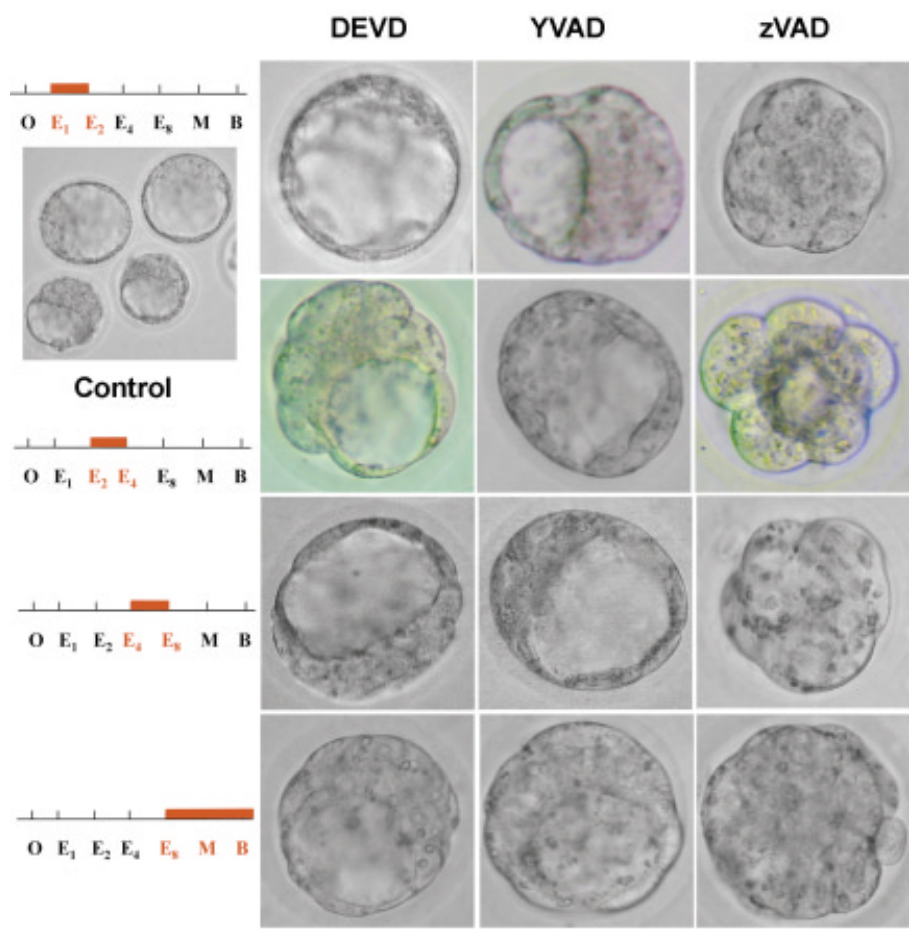

Fig. 2. Development of embryos when they were exposed to caspase inhibitors. Embryos were exposed according to the schedules indicated on the left. Embryos were exposed to the inhibitors between 1-cell and 2cell stages, or between 2-cell and 4-cell, 4-cell and 8-cell, or 8-cell through the time that controls reached expanded blastula, as shown in the panel labeled 'control' and photographed at that time. Neither DEVD-FMK (left column) nor YVAD-FMK (center column) seriously interfered with development, though the caspase inhibitors applied at 8-cell stage slightly slowed the expansion of the blastocoele. zVAD-FMK, however, impeded development at all stages, with the most severe effect being seen when the inhibitor was applied from 1-cell to 2-cell stage. None of the embryos exposed to zVAD successfully formed an expanded blastocyst.

In almost all cases development was blocked between 4 cell and early morula stage (8-16 cells-Table 3 ). When embryos were subjected to zVAD for either E1-E2 or E2-E4, the development stopped by $6-8$ cells with occasional embryos stopped at $4-5$ cells; 1 embryo of 66 reached 16 cells. For embryos exposed during E4E8 more embryos (26\%) reached 8 cells to almost early morula (Fig. 1 top, Table 3). When the embryos were exposed at E8 to blastula, they progressed to morula with an occasional embryo resembling early blastocyst. However although there appeared to be formation of a blastocoele the rest of the embryo did not look complete.

Progression of development was normal up to the 4 or 8 cell stage. Embryos exposed to the inhibitor as early as E1 continued with the normal pattern of cell division until 8 cell stage (Table 3 ). Up to this point we found no difference between the treated and the control even in the zVAD treated embryos. Our observation suggests that the loss of the cells or blockage of development, although set up at the early stages, was executed at stage between 8 cell and blastula. Furthermore we find that the earlier the exposure, the more severe the outcome. This finding suggests that caspases inhibited by zVAD do not interfere with the progression 
of cell division but do affect the progression of embryonic development when the embryo gets to compaction at the 8 cell stage. This timing also correlates with when we see the initial sign of embryonic cell death. Since this effect on the embryo is seen even when we use zVAD at the 1 to 2 cell stage, this factor must already be present or must act at this time and is not replaced as the cell divides, although the effect is manifest between the 8 cell and gastrula stage. Since this is the first time that we find embryonic cell death the factor(s) inhibited may be needed for both cell death and the progression of embryonic development.

\section{Cell death is not blocked and it may be enhanced by caspase inhibition}

We asked if application of the inhibitors affected any of the normally occurring, apoptotic (Weil, Jacobson, Coles, Davies, Gardner, Raff and Raff, 1996; Matwee, Betts and King, 2000) cell deaths. We compared cell death in the exposed embryo to that in the control, using annexin $\mathrm{V}$. We found no alteration of pattern of cell death during the developmental stages in any of the situations. However at the blastula stage while control, YVAD and DEVD exposed embryos showed normal patterns of cell death (one or two cells at the edge of the inner cell mass), the embryos exposed to zVAD showed extensive numbers of cells in the embryo positive for annexin V (Figure 3). Thus the low numbers of cells in zVAD treated embryos may result from loss of cells due to an increase in the number of cell deaths. Using Hoechst dyes we see fragmented nuclei (data not shown). Our findings suggest further that the normal pattern of cell death may not be caspase dependent, at least as determined by the inhibitors. Since we see no change in the death of the polar bodies we conclude that the death of the polar body may likewise be independent of caspases. Martinez et al. (Martinez, Rienzi, lacobelli, Ubaldi, Mendoza, Greco and Tesarik, 2002) consider that the death of at least the second polar body can involve caspases, but that of the first polar body does not. It is clear that the zVAD penetrated the embryos and that, although knockout of individual caspases may not seriously derange development, zVAD, which can inhibit several caspases simultaneously, does. Though we were unable to measure the intracellular concentration of any of the inhibitors, many researchers report biological effects at the concentrations we used (Foghsgaard, Wissing, Mauch, Lademann, Bastholm, Boes, Elling, Leist and Jaattela, 2001). We observed similar but less consistent (lower frequency) results in preliminary experiments using $50 \mu \mathrm{M}$ rather than $100 \mu \mathrm{M}$ zVAD (data not shown). Since cells can still die by apoptosis in this case our finding argues that caspases have a different role during embryonic compaction and gastrula formation and that their function begins at the single cell stage and may be part of maternal effect. It is known that, in addition to role of caspases such as caspase 8 in antigen-induced activation in the immune system (Newton and Strasser, 2003), caspases may function in situations of differentiation without cell death, such as in the case of the erythrocyte, keratinocyte and lens fiber (Abraham and Shaham, 2004). Thus the role of caspases in early mammalian development, or conversely the effect of the caspase inhibitor zVAD-FMK on other enzymes, deserves considerably greater attention. For instance, mouse embryos bearing knockouts for individual caspases typically develop well past implantation (Abraham and Shaham, 2004), as do APAF-1 knockouts (Yoshida, Kong, Yoshida, Elia,

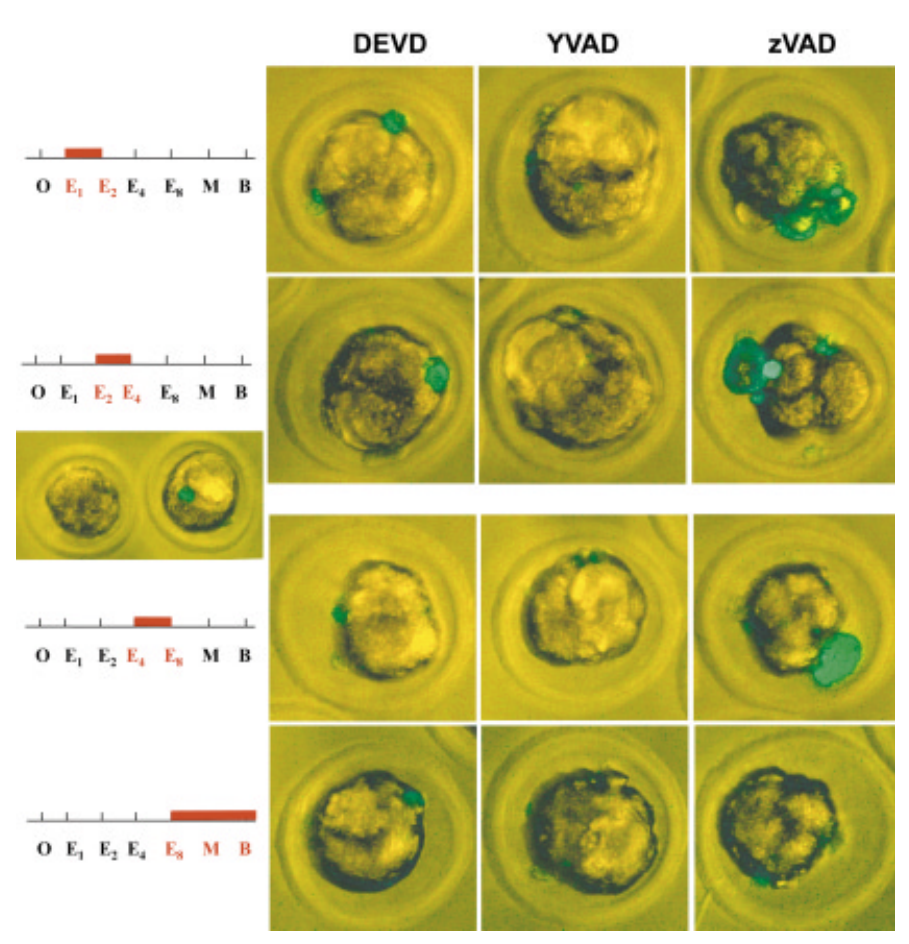

Fig. 3. Cell death in embryos exposed to caspase inhibitors. This experiment was similar to that displayed in Fig. 2, but preparations examined for exteriorization of phosphatidylserine (green annexin $V$ fluorescence). Death of polar bodies was not prevented by any of the inhibitors. In embryos exposed to zVAD-FMK at $E_{1}-E_{2}$ one or two embryonic cells died by the time that the embryo should have been entering expanded blastula period. For other embryos, the number of cell deaths seemed to expand, ultimately killing the embryo.

Hakem, Hakem, Penninger and Mak, 1998). It is possible that these embryos compensate for abnormalities engendered by failure of early caspase function, but investigation of these questions awaits the future.

\section{Experimental Procedures}

\section{Embryo retrieval}

All media came from Sigma (St. Louis, MO, USA). Female B6CBA mice were injected with PMSG (pregnant mare serum gonadotrophins). Two days later they were injected with hCG (human chorionic gonadotrophin) and mated with males overnight. The next day (day of plug), considered day 0.5 of gestation, the females were sacrificed and the fertilized eggs were removed as described in (Hogan and Constantini, 1986). We routinely retrieved about 85-100 embryos from 5-8 mice. Embryos were collected in M2 medium and then transferred to M16 for development and treatment. To get 8 cell stage embryos mothers were sacrificed two days after day of the plug appearance.

\section{Treatment}

The embryos were washed in M2 and placed in M16 covered with mineral oil. The embryos were then placed in a $37^{\circ} \mathrm{C}$ incubator with $5 \% \mathrm{CO}_{2}$. For situations in which we monitored the development of the embryos in vitro for several days the embryos were transferred to new media every day. The caspase inhibitors were obtained from Calbiochem (San Diego, CA, USA) and used at the final concentration of $100 \mu \mathrm{M}$. These concentrations were equivalent to those used for cultured cells by a number of 
investigators (Leist and Jaattela, 2001; Foghsgaard, Wissing, Mauch, Lademann, Bastholm, Boes, Elling, Leist and Jaattela, 2001). Embryos were inspected prior to exposure and any abnormal embryos were discarded at the start of the experiment. Typically the embryos were exposed beginning at the one cell zygote stage (E1), two-cell stage (E2), 4-cell stage (E4) and 8-cell stage (E8). They were exposed, either continuously in the presence of the caspase inhibitor continuously or they were placed in fresh inhibitor-free medium at the next cell division, i.e. exposed during $\mathrm{E} 1$ to $\mathrm{E} 2$, designated E1-E2. The embryos were monitored by light microscopy every day to verify stage and quality of development. The embryos were maintained until the controls reached blastula stage, usually the next day for the 8 cell embryos and 4 days when we started with one-cell embryos.

\section{Annexin $V$ treatment}

To identify apoptotic cells we tried several techniques and found that detection of exposure of phosphatidyl serine was very effective. Fluorescein-labeled annexin V was purchased from Immunotech (Marseille, France). Following the recommendation of the manufacturer, embryos were placed in $1 X$ annexin $V$ for 5 minutes. The amount of cell death was examined using confocal microscopy. Cells with green fluorescence were designated as dead cells.

\section{Acknowledgement}

We would like to thank the members of Centro Nacionalde Biotecnologia, Departamento de Inmunología y Oncología, Madrid for their help. This project was supported in part by a grant from the Ministerio de Educacion $y$ Cultura (Spain) to ZZ and NIH R15GM/AAG57614 to RAL.

\section{References}

ABRAHAM, M. C. and SHAHAM, S., (2004). Death without caspases, caspases without death. Trends Cell Biol. 14: 184-193.

CRYNS, V.L. and YUAN, J.Y. (1998). The cutting edge: caspases in apoptosis and disease. In When cells die: a comprehensive evaluation of apoptosis and programmed cell death. (Eds. Lockshin, R.A., Zakeri, Z. and Tilly, J.L.) New York, Wiley Liss, pp. 117-210.

FOGHSGAARD, L., WISSING, D., MAUCH, D., LADEMANN, U., BASTHOLM, L., BOES, M., ELLING, F., LEIST, M. and JAATTELA, M., (2001). Cathepsin B acts as a dominant execution protease in tumor cell apoptosis induced by tumor necrosis factor. J. Cel/ Biol153: 999-1010.

HANDYSIDE, A. H. and HUNTER, S., (1986). Cell division and death in the mouse blastocyst before implantation. Roux's Arch. Dev. Biol. 195: 519-526.

HARDY, K., (1997). Cell death in the mammalian blastocyst. Mol. Hum. Reprod. 3: 919-925.

HARDY, K., HANDYSIDE, A. H. and WINSTON, R. M., (1989). The human blastocyst: cell number, death and allocation during late preimplantation development in vitro. Development 107: 597-604.

HARVEY, N. L. and KUMAR, S., (1998). The role of caspases in apoptosis. Adv. Biochem. Eng Biotechnol. 62:107-28: 107-128.

HOGAN, B. and CONSTANTINI, F. L. E., (1986). Manipulating the Mouse Embryo: A Laboratory Manual.
JOZA, N., SUSIN, S. A., DAUGAS, E., STANFORD, W. L., CHO, S. K., LI, C. Y., SASAKI, T., ELIA, A. J., CHENG, H. Y., RAVAGNAN, L., FERRI, K. F., ZAMZAMI, N., WAKEHAM, A., HAKEM, R., YOSHIDA, H., KONG, Y. Y., MAK, T. W., ZUNIGA-PFLUCKER, J. C., KROEMER, G. and PENNINGER, J. M., (2001). Essential role of the mitochondrial apoptosis-inducing factor in programmed cell death. Nature 410: 549-554.

JURISICOVA, A., ROGERS, I., FASCIANI, A., CASPER, R. F. and VARMUZA, S. (1998). Effect of maternal age and conditions of fertilization on programmed cell death during murine preimplantation embryo development. Mol. Hum Reprod. 4: 139-145.

LEIST, M. and JAATTELA, M., (2001). Four deaths and a funeral: from caspases to alternative mechanisms. Nat. Rev. Mol. Cell Biol2: 589-598.

MARTINEZ, F., RIENZI, L., IACOBELLI, M., UBALDI, F., MENDOZA, C., GRECO, E. and TESARIK, J., (2002). Caspase activity in preimplantation human embryos is not associated with apoptosis. Hum. Reprod. 17: 1584-1590.

MATWEE, C., BETTS, D. H. and KING, W. A., (2000). Apoptosis in the early bovine embryo. Zygote 8: 57-68.

MOLEY, K. H., CHI, M. M., KNUDSON, C. M., KORSMEYER, S. J. and MUECKLER, M. M., (1998). Hyperglycemia induces apoptosis in pre-implantation embryos through cell death effector pathways. Nat. Med. 4: 1421-1424.

NEWTON, K. and STRASSER, A., (2003). Caspases signal not only apoptosis but also antigen-induced activation in cells of the immune system. Genes Dev. 17: 819-825.

PAMPFER, S. and DONNAY, I., (1999). Apoptosis at the time of embryo implantation in mouse and rat. Cell Death. Differ. 6: 533-545.

PAMPFER, S., VANDERHEYDEN, I., MCCRACKEN, J. E., VESELA, J. and DE HERTOGH, R., (1997). Increased cell death in rat blastocysts exposed to maternal diabetes in utero and to high glucose or tumor necrosis factor-alpha in vitro. Development 124: 4827-4836.

PIERCE, G. B., LEWELLYN, A. L. and PARCHMENT, R. E., (1989). Mechanism of programmed cell death in the blastocyst. Proc Natl. Acad. Sci U.S.A 86: 36543658.

THORNBERRY, N. A., (1999). Caspases: A decade of death research. Cell Death Differ. 6: 1023-1027.

VAUX, D. L., (1999). Caspases and apoptosis - biology and terminology. Cell Death Differ. 6: 493-494.

VAUX, D., (2004). Survival Factors. 257-274.In When cells die Il. (Eds. Lockshin, R.A. and Zakeri, Z.) New York, Wiley Liss, pp. 257-274.

WEIL, M., JACOBSON, M. D., COLES, H. S. R., DAVIES, T. J., GARDNER, R. L., RAFF, K. D. and RAFF, M. C., (1996). Constitutive expression of the machinery for programmed cell death. J. Cell Biol. 133: 1053-1059.

YOSHIDA, H., KONG, Y. Y., YOSHIDA, R., ELIA, A. J., HAKEM, A., HAKEM, R., PENNINGER, J. M. and MAK, T. W., (1998). Apaf1 is required for mitochondrial pathways of apoptosis and brain development. Cel/94: 739-750.

Received: November 2004

Reviewed by Referees: December 2004 Modified by Authors and Accepted for Publication: January 2005 